\title{
Carcinoma of Urinary Bladder and Subsequent Carcinoma of Lung: Rare Combination of Two Primary Carcinomas with Different Histopathology
}

\author{
Ibrahim Al Oraifi, Ikram Chaudhry, Aman Alfraj, Hadi Mutari, Shoukat Bojal and Irfan S Khan*
}

Department of Urology and Thoracic Surgery, King Fahad Specialist Hospital, Saudi Arabia

Submission: July 30, 2018; Published: August 16, 2018

*Corresponding author: Irfan S Khan, Department of Urology and Thoracic Surgery, King Fahad Specialist Hospital, Dammam, Saudi Arabia, Email: iconik@gmail.com

\section{Abstract}

These days multiple malignancies are encountered more frequently because of early diagnosis and recent advances in Chemotherapy / Radiotherapy, leading to prolonged survival with potential of developing a new malignancy. Transitional cell carcinoma of urinary bladder with subsequent development of carcinoma of lung is exceedingly rare. We report two cases of urinary bladder carcinoma with latter development of primary lung carcinoma.

\section{Introduction}

Transitional cell carcinoma of urinary bladder is the most common malignant neoplasm of the urinary tract. Globally the incidence of urinary bladder cancer is $10.1 \%$ and $2.5 \%$ per 100,000 in male and female respectively. The urinary bladder cancer that is confined to mucosa (stage Ta+ carcinoma insitu) and limited to lamina propria (T1) [1] are grouped together as non - muscle invasive bladder tumors (NIMBC). The overall incidence of the patients who harbor NIMBC IS 75-85\%. With recent advances in chemotherapy /Radiotherapy and early

Case 1 diagnostic tools the survival rate has markedly increased in patients with urinary bladder cancer but on the other hand incidence of second primary cancer has increased by $16 \%$ according to NIC surveillance [2]. For non-muscle invasive bladder cancer, the probability of recurrence at 5 years ranges from $31 \%$ to $78 \%$ whereas the risk of distant metastasis is extremely low. We present two cases of urinary bladder cancer that subsequently developed pulmonary nodule suspected to be metastasis. Perioperative frozen section revealed primary lung cancer.

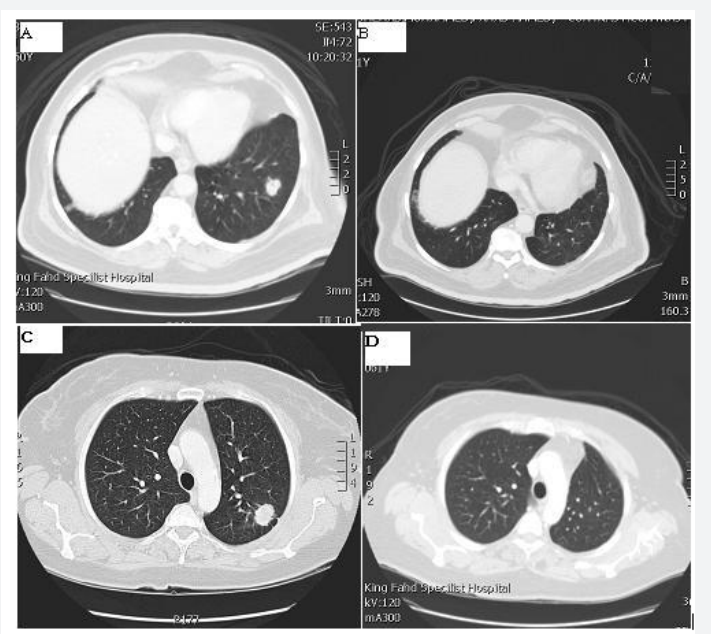

Figure 1: Case 1 (A) Chest roentgenogram showing a left lower pulmonary nodule. (B) CT Thorax of the same patient 12 months after surgery showing no recurrence. Case 2 (C) CT Thorax showing a pulmonary nodule in the left upper lobe. (D) CT Thorax of the same patient 24 months after surgery showing no recurrence. 
A 50 years old male smoker, diabetic known hypertensive presented in 2009 with painless hematuria flexible urinary bladder examination revealed a bladder tumor. He underwent transurethral resection of bladder tumor (TURBT), histophalogy report showed superficial bladder cancer. He was initially treated with intravesical Bacilli Calmette Guerin therapy (BCG) follow up check cystoscopy revealed a recurrence of tumor which was treated with surgical resection and intravesical installation of mytomycin and BCG and systemic chemotherapy (Gemcitabine and Cisplatin). Further follow cystoscopic examination showed residual disease and biopsy report revealed residual high grade urothelialial carcinoma with no muscle invasion. CT scan of chest performed in 2012 showed left lung nodule in lower lobe suspecting metastasis (Figure 1). The lesion was approached through left postero lateral mini thoracotomy and biopsy was taken for frozen section. Histopathology report revealed primary squamous cell carcinoma of lung, based on this plan was changed from metastatectomy to left lower lobectomy. Patient post-operative recovery was uneventful and follows up CT scan of thorax after two years showed no recurrence.

\section{Case 2}

A lady age 60 years was diagnosed in 2001 with superficial transitional cell carcinoma of urinary bladder. She was treated with TURBT and later on intravesical installation of BCG. Surveillance cystoscopic examinations were normal. In 2011 CT scan of chest showed a nodule in left lung upper lobe (Figure 2). Patent underwent left mini thoracotomy and frozen section biopsy showed primary adenocarcinoma of lung, therefor left upper lobectomy was performed. Her post-operative recovery was uneventful and to date she is disease free according to yearly CT scans of chest report.

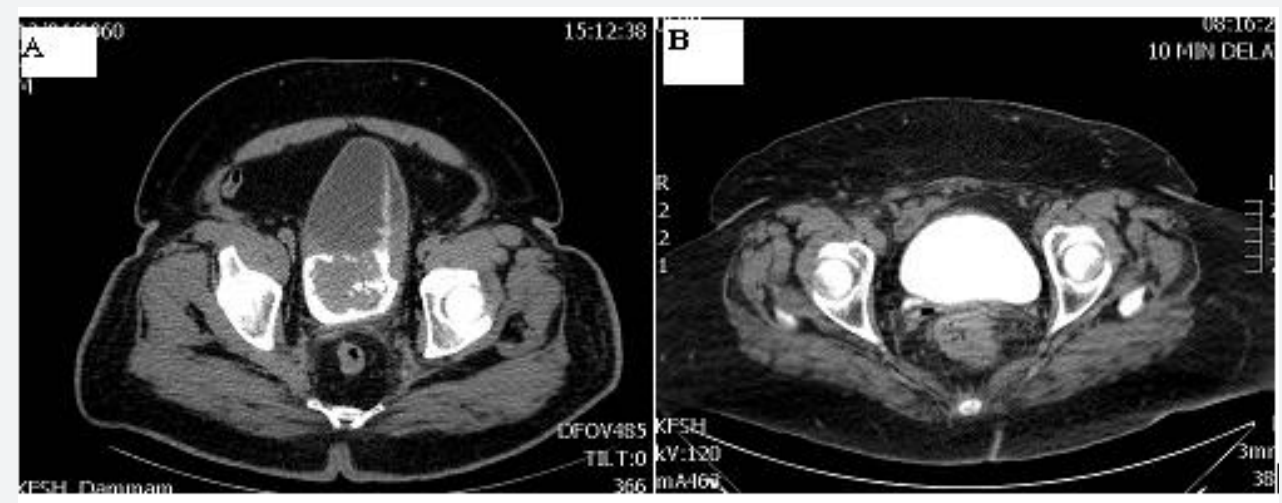

Figure 2: (A) Case 1 CT scan of abdomen and pelvis showing recurrence of tumor in the urinary bladder. (B) Case 2 CT scan of abdomen and pelvis showing no tumor in urinary.

\section{Discussion}

The Urinary bladder cancer is more common in smokers and in those who are exposed to Aromatic amines (paint, iron, aluminum printing, tar and gas industries) [3]. The development of second primary cancer is multifactorial either the genetic mutation, treatment related or smoking as shared etiology in urinary bladder and lung cancer. Incidence if lung cancer in smokers is $20-40$ folds higher in comparison to nonsmokers. Ninety percent of patients with lung are smokers while 20 $\%$ of smokers develop lung cancer [4,5]. On the other hand, the incidence of urinary bladder cancer is directly related to duration and number of cigarette packs consumption. Two out of three patients with urinary bladder cancer are smoker. Livi \& Germic et al. [6] reported that incidence of two primary cancers in smokers is $10-20 \%$ [6]. Certain urological surgical procedures such as uretro sigmoidostomy may induce second primary neoplasm [7].

The superficial urinary bladder cancer rarely progress to invasive or metastatic stage. The FINNISH cancer registry data reported by L Teppo et al. [8] showed in 1300 second primary cancer in 77548 lung cancer patients and among them there were 140 cases of urinary bladder cancer [8]. The diagnosis of urinary bladder cancer is based on several factors, including patients' presenting symptoms, urine examination and radiological imaging modalities. The most common presenting symptoms are hematuria, but less frequently may also include increased urinary frequency, dysuria and bladder outlet obstruction. Urine cytology is can be positive for malignant cells in high grade tumors and in carcinoma in situ, but is usually negative in low grade tumors. Imaging modalities most commonly employed to reach the diagnosis are urinary tract ultrasound scan and CT scan of abdomen and pelvis.

Preoperative work up and correct diagnosis and staging work up is essential for planning appropriate treatment, better prognosis and long term survival. Although the survival of patients depends time interval between two primaries and histological type and grading superficial urinary bladder cancer normally don't progress to invasive or metastatic stage despite of that it is most common malignancy of urogenital system. A few cases of superficial bladder cancer with pulmonary metastasis has been reported in medical literature [9]. It is exceedingly rare that subsequent to urinary bladder cancer patient develop primary lung cancer. M Vainrib \& Leiobovtich et al. [10] reported retrospective analysis of 25 patients between 
1990 to 2005 who were diagnosed with dual malignancy urinary bladder cancer and lung cancer, they found that in $84 \%$ of cases the bladder was first primary tumor site and in $60 \%$ of case it was second primary tumor site [10]. The cases we report here both were diagnosed radiological as metastasis, but we decided to perform frozen section to confirm diagnosis. This changed our management plan. A full histopathology report revealed two different cancers (Figure 3A-3D).

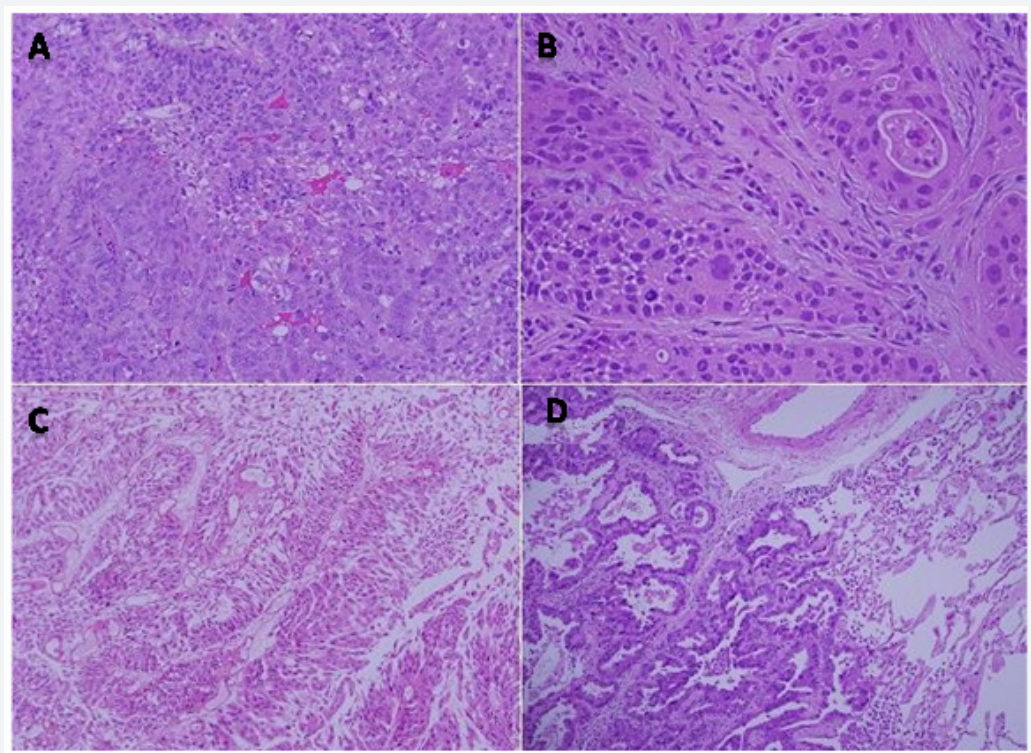

Figure 3: (A) Photomicrograph of the original urinary bladder tumor of case1 showing high grade urothelialial carcinoma. (H\&E 400X). (B) Lung tumor of case 1 showing invasive poorly differentiated squamous cell carcinoma. (H\&E 400X). (C) Urinary bladder tumor of case 2 showing low grade urothelialial carcinoma. Note the papillary architecture and the low-grade cytology. (H\&E 200X). (D) Lung tumor in case 2 featuring adenocarcinoma with infiltration of the lung parenchyma by malignant glands. (H\&E 200X).

\section{Conclusion}

In conclusion Carcinoma of Urinary Bladder and Subsequent Carcinoma of Lung is very rare combination of two Primary Carcinomas with different Histopathology. A frozen section biopsy is very useful in such case because this will not only help for appropriate surgical procedure such as metastatectomy or lung lobectomy but also has great impact on prognosis and longterm survival of patient. Therefore, we strongly recommend the use of frozen section in such cases.

\section{References}

1. David W Dougherty, Victoria K Gonsorcik, Lewis E Harpster, J C Trussell, Joseph J Drabick (2009) Superficial bladder cancer metastasis to the lungs: two case reports and review of the literature. Urology 73(1): 210 .

2. Khanal A, Budhathoki N, Singh VP, Shah BK (2017) Second Primary Malignancy in Bladder Carcinoma - A Population-based Study. Anticancer Res 37(4): 2033-2036.

3. J Lorenzo Bermejo, J Sundquist, K Hemminki (2009) Bladder cancer in cancer patients: population-based estimates from a large Swedish study, British Journal of Cancer 101(7): 1091-1099.
4. Berenn P, Pogillot O, Cordier S, Greiser E, Schill W, et al. (2000) Cigarette smoking and bladder cancer in man, pooled analysis of 12 case- control study. Int J Cancer 86(2): 289-294.

5. Yun YH, Jung KW, Bae JM, Lee JS, Shin SA, et al. (2005) Cigarette smoking and Cancer incidence in adult men: national health insurance corporation study. Cancer Detect Prev 29(1): 15-24.

6. Ozlu T, Bulbul Y (2005) Smoking and cancer. Tuberk Toraks 53: 200209.

7. Ray P, Sharifi R, Ortolano V, Guin P (1983) Involvement of genitourinary system in multiple malignant primary neoplasm's review. J Clin Oncol 1: $574-581$.

8. Teppo L, Salminen E, Pukkala E (2001) Risk of new primary cancer among patients with lung cancer of different histological type. Eur J Cancer 37(5): 613-619.

9. Tanis PJ, Zondervan PA, Van de Wiel BA (2005) Surgery for isolated lung metastasis in two patients with bladder cancer. Urology 66: 881.

10. Koh KB, Rogawski K, Smith PH (1994) Cavitating pulmonary metastasis from superficial transitional cell carcinoma of urinary bladder: Case report. Scand J Urol Nephrol 28(2): 201-202. 
Your next submission with Juniper Publishers will reach you the below assets

- Quality Editorial service

- Swift Peer Review

- Reprints availability

- E-prints Service

- Manuscript Podcast for convenient understanding

- Global attainment for your research

- Manuscript accessibility in different formats

( Pdf, E-pub, Full Text, Audio)

- Unceasing customer service

Track the below URL for one-step submission

https://juniperpublishers.com/online-submission.php 